\title{
Pediatric Dysphagia: The 10th Anniversary Issue
}

$\mathrm{I}_{\mathrm{t} \text { has been a decade since Joan Arvedson }}$ and Maureen Lefton-Greif edited an invaluable two-part series on Pediatric Dysphagia for Seminars in Speech and Language (Volume 17, Number 4 and Volume 18, Number 1). At that time, it was one of Seminars' most frequently completed activities. In the decade since the publication of that series, treatment of children with dysphagia has continued to evolve; it continues to be a pressing health issue for which many practicing speech-language pathologists (SLPs) urgently seek guidance. Thus, it is fitting that we re-address and update this important area of practice, which has grown in scope and complexity.

It is obvious that, in the interim since Seminars last addressed pediatric dysphagia, much has changed. More and differing populations of infants and children are being identified with this major health condition with each passing year The increase in population need has naturally brought more and more SLPs into this area of practice, many of whom may have had very little structured educational background in the area. For them, this issue can serve, as did its predecessor, as a valuable guide to the large literature being created in this area of clinical need.

The scientific and evidence bases for SLP practice are rapidly evolving and must address advances in the medical and surgical treatment of conditions related to swallowing dysfunction, the understanding of interactions between respiration and swallowing and swallowing dysfunction, the understanding of nutrition and hydration needs of infants and children with feeding and swallowing disorders, identification of effective interventions, and the more nuanced appreciation of the varied presentations that may signal dysfunction. Finally, the regulatory landscape has changed. There are new federal mandates and guidelines for provision of services to children with swallowing problems. It is not enough to know how to evaluate and treat - one must be cognizant of legal and ethical concerns that arise during the process.

In short, the list of emerging bodies of knowledge that impact effective diagnosis and treatment of pediatric feeding and swallowing disorders is quite long, as readers will soon appreciate. I was extremely fortunate to have Maureen and Joan agree to compile this 10th "Anniversary" issue of their first effort. I know that readers of Seminars will find this volume as invaluable as its earlier companions.

$$
\begin{array}{r}
\text { Nan Bernstein Ratner, Ed.D. }{ }^{1} \\
\text { Co-Editor in Chief }
\end{array}
$$

${ }^{1}$ Professor and Chairman, Department of Hearing and Speech Sciences, University of Maryland, College Park, Maryland.

Pediatric Dysphagia: The 10th Anniversary Issue; Guest Editors, Maureen A. Lefton-Greif, Ph.D., CCC-SLP, BRS-S, and Joan C. Arvedson, Ph.D., CCC-SLP,

\section{BC-NCD, BRS-S.}

Semin Speech Lang 2007;28:159-160. Copyright (C) 2007 by Thieme Medical Publishers, Inc., 333 Seventh Avenue, New York, NY 10001, USA. Tel: +1(212) 584-4662.

DOI 10.1055/s-2007-984721. ISSN 0734-0478. 